\title{
Health Related Quality of Life in Patients with Acute Myocardial Infarction: A Group-Based Trajectory Analysis
}

\author{
Chieh Yu Liu ${ }^{1}$, Hsiu Hua Cheng ${ }^{2}$, Heng Hsin Tung ${ }^{3}$, Ji Hung Wang ${ }^{4}$ and Shiow Luan Tsay*5 \\ ${ }^{1}$ PhD, Statistician, Associate Professor, National Taipei University of Nursing and Health Science
}

${ }^{2} P h D$ candidate, National Taipei University of Nursing and Health Science, Taiwan

${ }^{3}$ FNP, PhD, Professor of National Yang Ming University, College of Nursing; Consultant, Tungs' Taichung Metro Habor Hospital, Taiwan

${ }^{4} \mathrm{MD}$, Division of Cardiology, Buddhist Tzu-Chi General Hospital, Taiwan

${ }^{5}$ PhD, Professor, College of Nursing and Health Sciences, Da-Yeh University, Taiwan

Submission: May 01, 2018; Published: May 08, 2018

*Corresponding author: Shiow Luan Tsay, PhD, Professor, College of Nursing and Health Sciences, Da Yeh University, University Rd., Dacun, Changhua 51591, Taiwan, Tel: 886+972796506, Email: sltsay0308@gmail.com

\begin{abstract}
Objective: Very few studies have investigated the trajectory of health-related quality of life (HRQoL) in acute myocardial infarction (AMI) patients. To identify AMI trajectory groups and patient characteristics of those in the lowtrajectory as related to HRQoL.

Methods: Of the total of 102 participants were collected by demographic questionnaire at baseline and at 1 month, 3 months, and 6 months, using the 12-Item Short Form Health Survey (SF-12). The group-based trajectory model (GBTM) was applied to identify the optimal trajectory groups in terms of HRQoL.
\end{abstract}

Results: Among the three trajectory subgroups for the physical component summary (PCS), as identified by GBTM, the second group (34.1\% of participants) showed a statistically significant decreasing trend (slope $\beta=-1.45, p=0.0221$ ). Among the four trajectory subgroups for the mental component summary (MCS) identified by GBTM, however, the second group (35.98\% of participants) showed a decreasing trend (slope $\beta=-1.38, p=0.005)$, and the third group (17.16\% of participants) showed a increasing trend (slope $\beta=2.90, p=0.001$ ).

Conclusions: Three PCS and four MCS trajectories were identified. Patient characteristics of those in the low-trajectory trend for HRQoL also were identified. Notably, obesity is an important modifiable factor in regard to the low-trajectory trend for HRQoL.

Keywords: Acute Myocardial Infarction; Group-Based Trajectory Model; Health Related Quality of Life

Abbreviations: ACEI: Angiotensin Converting Enzyme Inhibitor; AMI: Acute Myocardial Infarction; BMI: Body Mass Index; CABG: Coronary Artery Bypass Grafting; CCI: Charlson Comorbidity Index; CHD: Coronary Heart Disease; CNORM: Censored Normal; CPK: Creatine Phospho Kinase; DM: Diabetes Mellitus; GBTM: Group Based Trajectory Model; HRQOL: Health Related Quality Of Life; ICP: Initial Chest Pain; IRB: Institutional Review Board; LVEF: Left Ventricular Ejection Friction; LOS: Length Of Stay; MCS: Mental Component Score; NSTEMI: Non-STElevation Myocardial Infarction; NYHA: New York Heart Association; PCI: Percutaneous Coronary Intervention; PCS: Physical Component Score; PTCA: Percutaneous Transluminal Coronary Angioplasty; SF-12: 12 Item Short Form Health Survey; STEMI: ST-Elevation Myocardial Infarction

\section{Introduction}

Acute myocardial infarction (AMI) is one of the major causes of death worldwide. Due to advances in medical technology and treatment, patients' survival rate has risen dramatically. Thus, the quality of life of AMI survivors has become an important indicator as an outcome of care. Many researchers conduct cohort studies to investigate patterns and predict factors related to quality of life in coronary heart disease (CHD) patients. Some studies have found that quality of life may predict a poor prognosis and increase the mortality rate in myocardial infarction patients [1-3]. Due to the variety of CHDs, targets selected by research institutes for tracking health-related quality of life (HRQOL) trajectories include not only patients with invasive treatment, such as cardiac surgery or coronary artery interventions, but also others who did not undergo such invasive treatment. Therefore, the conclusions of these studies are inconsistent. Research has revealed that the quality of life of patients with myocardial infarction improves over a period of time from 1 month up to 2 years [4-7]. At 2 months, improvement in body pain and mental health begins. There is a slower recovery in physical functioning and emotional role limitations up to 12 months [3]. Some believe that quality of life declines over time [8]. Most studies have suggested the predictors of change include age, gender [9-11], smoking [4,7,8,12], social 
support $[1,13,14]$, type of AMI, severity of myocardial infarction, persistence of symptoms [4,7], and anxiety and depression [1,1517]. One study enrolled 3,501 AMI patients (67\% women) aged 18-55 years to examine the patterns of recovery in the year after AMI. Participants were scored three times (baseline, 1 month, and 12 months) for angina symptoms, disease-specific quality of life, and physical and mental functioning. The results revealed that women had significantly lower health status in the Physical Component Score (PCS) and Mental Component Score (MCS) [9]. Another study, which investigated coronary artery bypass grafting (CABG) patients, found that women have higher general health status than do men and that the improvement in mental health status starts 2 months after surgery [6].

Repeated-measure Quality of Life surveys for AMI patients are mostly mean score-trend surveys and assume that each case should be consistent. In fact, the quality-of-life trajectory of each patient is different; thus, it is not appropriate to define the trajectory by mean scores. Thus, some studies have started to use different methods to identify the physical and psychological symptoms and quality-of-life trajectories of CHD patients. Some studies that have investigated depression in CHD patients have found three to four depression trajectories $[18,19]$. Other studies have investigated depression and HRQOL trajectories of persons with CHD. One study followed up on patients over one year after CABG. The results showed two trajectories, one for PCS and one for MCS. The researchers identified an improvers group and a non-improvers group in both PCS and MCS. Profile of Mood States (POMS) vigor-activity and New York Heart Association (NYHA) classification were significant predictors for the nonimprovers group for PCS, whereas the POMS depression-dejection and manual occupation were significant predictors of the nonimprovers group for MCS [20]. Another study investigated 6,890 participants over the course of 21 years and used the groupbased trajectory model (GBTM) to identify psychological distress trajectories. The results showed four distinct trajectories. CHD and the risk factors for obesity and smoking were significantly associated with intermediate to low (OR 1.70, 95\% CI 1.08-2.68) and persistently high (OR 1.92, 95\% CI 1.16-3.19) psychological distress trajectories [19]. There are very few studies, however, that investigate the HRQOL trajectory in AMI patients. Thus, the purpose of this study is to apply GBTM to analyze individual trajectories and cluster similar physiological and psychological quality of life trajectory in AMI subjects.

\section{Methods}

The study is a prospective cohort study of HRQOL trajectories in AMI patients. We included AMI patients from two hospitals in eastern Taiwan from 2014 to 2016. Inclusion criteria were age 18 years and above, able to communicate verbally, myocardial infarction without mechanical complications (such as a left ventricular aneurysm, acute mitral insufficiency, or papillary muscle rupture), and absence of cancer or neurological or psychiatric disorders. Type II myocardial infarction was excluded.
After a complete description of the study was given to the participants, their written consent was obtained. Ethical approval for the study was obtained from the institutional review board (IRB) of the two hospitals that participated the study (Approval No: 14-04-007 \&IRB103-13-B). There were 102 participants in the baseline examination. Clinical data were collected from medical records. We interviewed participants at baseline, 1 month, 3 months, and 6 months, using the 12-Item Short Form Health Survey (SF-12) questionnaire, in the outpatient department or by telephone interview. We used GBTM to analyze the HRQOL trajectory of participants [21,22].

\section{Demographic and Clinical Data Collection}

Data on age, sex, employment, education level, race/ethnicity, and marital status were drawn from the survey questionnaire at the first interview. We used medical records to obtain data on the participants' medically related attributes, smoking, and alcohol consumption (Yes/No). Body mass index (BMI) was measured, and obesity was defined as $\mathrm{BMI} \geq 27 \mathrm{~kg} / \mathrm{m} 2$. Other medical records data included left ventricular ejection friction (LVEF), measured by an echocardiogram; AMI-specific information, such as types of AMI (STEMI/NSTEMI [ST-elevation MI/non-ST-elevation $\mathrm{MI}$ ), history, and number of myocardial infarctions; location of myocardial infarction as proven in coronary angiography; and types of reperfusion therapy (e.g., percutaneous coronary intervention [PCI]). AMI severity was evaluated with the Killip classification.

\section{Measurement of Health Related Quality of Life}

At each interview, participants responded to the SF-12 to evaluate the level of HRQOL [22]. The SF-12 is derived from the SF-36 Health Survey, which is used to evaluate the well-being of patients with chronic conditions. The 12 items include two on physical functioning, two on role limitations due to physical health problems, one on body pain, one on general health perceptions, one on vitality, one on social functioning, two on role limitations due to emotional problems, and two on general mental health (psychological distress and psychological well-being). The score is calculated by computer software, and the results are presented in two main components: PCS and MCS scores. The score range is $0-100$ for each component, with a higher score as indicating better quality of life. PCS and MCS have been shown to have high reliability and high internal consistency with a test-retest of 0.89 for PCS and 0.76 for MCS [19].

\section{Statistical Analyses}

Trajectories of quality of life were defined using GBTM, which identify clusters of individuals (trajectory groups) with a similar trajectory over time [21]. GBTM is a statistical method that is designed to identify an optimal number of trajectory groups as well as the shape and size of different trajectory groups in the data. The model selection relied on Bayesian information criterion and Akaike's information criterion to determine the optimal number of trajectories: lower absolute values correspond 


\section{JOJ Nursing \& Health Care}

to better fit. We hypothesized that patients with AMI would have different trajectories over time according to demographics and the characteristics of disease. We use the censored normal (CNORM) model for modeling the conditional distribution of SF-12 data, estimating the parameters, standard errors, group membership probabilities, and $\theta$. CNORM is appropriate for continuous data that are approximately normally distributed, with or without censoring. The data fit well in linear and quadratic trajectories in both PCS and MCS. GBTM was performed using SAS(SAS, version 9.2, Cary, NC).

\section{Results}

Table 1: Demographic characteristics.

\begin{tabular}{|c|c|c|}
\hline Variable & $\mathbf{n}$ & $\%$ \\
\hline \multicolumn{3}{|c|}{ Gender } \\
\hline Male & 80 & 78.4 \\
\hline Female & 22 & 21.6 \\
\hline \multicolumn{3}{|c|}{ Age } \\
\hline $20-39$ & 2 & 2.0 \\
\hline $40-49$ & 13 & 12.7 \\
\hline $50-59$ & 24 & 23.5 \\
\hline $60-69$ & 39 & 38.2 \\
\hline $70-79$ & 16 & 15.7 \\
\hline$>80$ & 8 & 7.8 \\
\hline \multicolumn{3}{|c|}{ Education } \\
\hline High school or below & 85 & 83.3 \\
\hline Some college or above & 16 & 16.7 \\
\hline \multicolumn{3}{|c|}{ Employment } \\
\hline Yes & 55 & 53.9 \\
\hline No & 47 & 46.1 \\
\hline \multicolumn{3}{|c|}{ Marital status } \\
\hline Single & 23 & 4.9 \\
\hline Married & 79 & 77.5 \\
\hline \multicolumn{3}{|c|}{ Living alone } \\
\hline Yes & 19 & 18.6 \\
\hline No & 83 & 81.4 \\
\hline \multicolumn{3}{|c|}{ Smoking } \\
\hline Yes & 39 & 38.2 \\
\hline No & 63 & 61.8 \\
\hline \multicolumn{3}{|c|}{ Alcohol } \\
\hline Yes & 36 & 35.3 \\
\hline No & 66 & 64.7 \\
\hline
\end{tabular}

Table 2: Clinical characteristics of AMI patients.

\begin{tabular}{|c|c|c|}
\hline Variable & n & \% \\
\hline \multicolumn{2}{|c|}{ BMI classification } & 1.0 \\
\hline Underweight $(<18.5 \%)$ & 1 & 25.5 \\
\hline Normal weight $(18.5-23.9 \%)$ & 26 & 32.4 \\
\hline Overweight $(24-26.9 \%)$ & 33 & 24.5 \\
\hline Mild obese $(27-29.9 \%)$ & 25 & 15.7 \\
\hline Moderate obese $(30-34.9 \%)$ & 16 & 1.0 \\
\hline Severe obese $(>35 \%)$ & 1 & \\
\hline
\end{tabular}




\section{JOJ Nursing \& Health Care}

\begin{tabular}{|c|c|c|}
\hline \multicolumn{3}{|c|}{ DM } \\
\hline Yes & 42 & 58.8 \\
\hline No & 60 & 41.2 \\
\hline \multicolumn{3}{|c|}{ AMI Type } \\
\hline STEMI & 49 & 48.0 \\
\hline NSTEMI & 53 & 52.0 \\
\hline \multicolumn{3}{|c|}{ AMI numbers } \\
\hline First time & 86 & 84.0 \\
\hline Second time & 13 & 13.0 \\
\hline Third time & 1 & 1.0 \\
\hline Fourth time & 2 & 2.0 \\
\hline \multicolumn{3}{|c|}{ Reperfusion therapy } \\
\hline PCI & 87 & 85.3 \\
\hline PTCA & 7 & 6.9 \\
\hline None & 7 & 6.9 \\
\hline \multicolumn{3}{|c|}{ Killip classification } \\
\hline $\mathrm{I}$ & 28 & 27.5 \\
\hline II & 33 & 32.4 \\
\hline III & 23 & 22.5 \\
\hline IV & 18 & 17.6 \\
\hline \multicolumn{3}{|c|}{ Occlusive Vessels } \\
\hline One vessel & 42 & 41.2 \\
\hline Two vessels & 28 & 27.4 \\
\hline Three vessels & 32 & 31.4 \\
\hline \multicolumn{3}{|c|}{ LVEF } \\
\hline $10-50 \%$ & 42 & 56.0 \\
\hline$>51 \%$ & 33 & 44.0 \\
\hline \multicolumn{3}{|c|}{ Lipid lower agent } \\
\hline Yes & 90 & 88.2 \\
\hline No & 12 & 11.8 \\
\hline \multicolumn{3}{|c|}{ Anti platelet therapy } \\
\hline Yes & 101 & 99.0 \\
\hline No & 1 & 1.0 \\
\hline \multicolumn{3}{|c|}{ ACEI } \\
\hline Yes & 58 & 56.9 \\
\hline No & 44 & 43.1 \\
\hline \multicolumn{3}{|c|}{ Beta-Blocker } \\
\hline Yes & 62 & 60.8 \\
\hline No & 40 & 39.2 \\
\hline
\end{tabular}

STEMI: ST-elevation myocardial infarction, NSTEMI: non-ST-elevation myocardial infarction, PCI: percutaneous coronary intervention, PTCA percutaneous transluminal coronary angioplasty, DM: diabetes mellitus, ACEI: angiotensin-converting-enzyme inhibitor

Table 3: Descriptive of clinical variables.

\begin{tabular}{|c|c|c|c|}
\hline Variable & Mean & (SD) & $(11.71)$ \\
\hline Age & 62.75 & $(3.66)$ & $34-93$ \\
\hline BMI & 26.31 & $(13.97)$ & $18-36$ \\
\hline LVEF & 47.97 & $(1298.16)$ & $1-4875$ \\
\hline CPK & 1009.83 & \\
\hline
\end{tabular}




\begin{tabular}{|c|c|c|c|}
\hline AMI Times & 1.21 & $(0.55)$ & $1-4$ \\
\hline LOS & 6.06 & $(4.74)$ & $1-26$ \\
\hline CCI & 2.01 & $(1.65)$ & $1-10$ \\
\hline ICP Score & 7.37 & $(2.50)$ & $0-10$ \\
\hline
\end{tabular}

BMI: body mass index, LVEF: left ventricular ejection friction, CPK: Creatine-phospho-kinase, LOS: length of stay, CCI: Charlson co morbidity index, ICP: initial chest pain

As seen in Tables 1-3, 102 AMI patients (age $62.75 \pm 11.71$ years; $78.4 \%$ men) participated in the study. Most of participants (73.5\%) were overweight or obese, and $58.8 \%$ were diabetic. Of the participants, $83.3 \%$ were first-time AMI patients, $44 \%$ had proven LVEF impairment ( $<50 \%$ ), 52\% had NSTEMI, $85.33 \%$ underwent PCI, and $72.5 \%$ of experienced AMI severity greater than Killip II (Killip II, 32.4\%; III, 22.5\%; IV, 17.6\%) (Table 2). The average length of stay was 6.1 days. Participants were assessed four times: during hospitalization after AMI (T1), 1 month (T2; $\mathrm{n}=79$ ), 3 months (T3; $\mathrm{n}=76$ ) and 6 months (T4; $\mathrm{n}=76$ ). Three patients $(2.9 \%)$ died during the follow-up period, $23(22.5 \%)$ patients were lost to follow-up or refused to continue in the study, and 76 (74.5\%) completed the study (Tables 1-3).

\section{Trajectories of PCS}

By using GBTM, three trajectory sub-groups of PCS were identified. Table 4 presents the descriptive characteristics of the participants by their membership in a PCS trajectory. The results suggest that male gender, 60 years or older, non-smoker, non-obese, and NSTEMI participants were overrepresented in the persistently intermediate trajectory. The corresponding percentages in each group were: males, 19\%,34\%, 47\%; age 60 years and older, 29\%, 37\%, 35\%; smokers, 27\%, 27\%, 47\%; and obese participants, $23 \%, 45 \%, 77 \%$ (Table 4 ). The results in Table 5 show that only the second group (34.18\% of participants) had a statistically significant linear trend $(t=-1.45$, $p$-value $=0.02)$. We refer to Group 1 as the "persistent low trajectory" group because the subjects in this group showed low PCS scores at the starting point that remained low over time. The estimated probability of membership was $23.6 \%$. The third group (42.3\%) was referred to as the "persistent high trajectory" group because the individuals in this group exhibited baseline scores in PCS that are comparable to those of the general population and that steadily increased over time (Table 4). Figure 1 shows the three trajectories of the three sub-groups. The first group (23.6\%) comprises individuals with a constant intermediate range scores for PCS. This group is characterized by a slight increase in scores at the time of the second interview that then gradually decline somewhat over the observation period. This group is called the "persistent intermediate trajectory" group; the slope coefficient, however, did not show statistical significance.

Table 4: Descriptive characteristics of the participants by trajectories of PCS.

\begin{tabular}{|c|c|c|c|c|c|}
\hline \multicolumn{6}{|c|}{ Trajectory } \\
\hline \multicolumn{2}{|c|}{ Variable } & \multirow{2}{*}{$\begin{array}{c}\text { All } \mathbf{n}=\mathbf{7 6} \mathbf{n}(\mathbf{\%}) \\
58(76.3)\end{array}$} & \multirow{2}{*}{$\begin{array}{c}\begin{array}{c}\text { Persistent Low } \\
\text { n = 18 n (\%) }\end{array} \\
11(61.1)\end{array}$} & \multirow{2}{*}{$\begin{array}{c}\begin{array}{c}\text { Persistent } \\
\text { Intermediate } \\
\mathbf{n = 2 6} \mathbf{n}(\%)\end{array} \\
20(76.9)\end{array}$} & \multirow{2}{*}{$\begin{array}{c}\begin{array}{c}\text { Persistent High } \\
\text { n = } 32 \text { n (\%) }\end{array} \\
27(84.4)\end{array}$} \\
\hline Gender & Male & & & & \\
\hline & Female & $18(23.7)$ & $7(38.9)$ & $6(23.1)$ & 5 (15.6) \\
\hline \multirow[t]{2}{*}{ Age } & $18-59$ & $27(35.5)$ & $4(22.2)$ & $8(30.8)$ & $15(46.9)$ \\
\hline & $60-85$ & $49(64.5)$ & $14(77.8)$ & $18(69.2)$ & 17 (53.1) \\
\hline \multirow[t]{2}{*}{ Employment } & Yes & $41(53.9)$ & $6(33.3)$ & $16(61.5)$ & 19 (59.4) \\
\hline & No & 35 (46.1) & $12(66.7)$ & $10(38.5)$ & $13(40.6)$ \\
\hline \multirow[t]{2}{*}{ Living alone } & Yes & $10(13.2)$ & $1(5.6)$ & $0(0)$ & $9(28.1)$ \\
\hline & No & $66(86.8)$ & $17(94.4)$ & $26(100)$ & 23 (71.9) \\
\hline \multirow[t]{2}{*}{ Smoking } & Yes & $30(39.5)$ & 8 (44.4) & $8(30.8)$ & $14(43.8)$ \\
\hline & No & $46(60.5)$ & $10(55.6)$ & $18(69.2)$ & $18(56.3)$ \\
\hline \multirow[t]{2}{*}{ Alcohol } & Yes & $28(36.8)$ & $8(44.4)$ & 7 (26.9) & $13(40.6)$ \\
\hline & No & $48(63.2)$ & $10(55.6)$ & $19(73.1)$ & $19(59.4)$ \\
\hline \multirow[t]{2}{*}{ BMI } & Non-obese & $45(59.2)$ & $7(38.9)$ & $14(53.8)$ & $24(75.0)$ \\
\hline & Obese & $31(40.8)$ & $11(61.1)$ & $12(46.2)$ & $8(25.0)$ \\
\hline \multirow[t]{2}{*}{ AMI type } & STEMI & 37 (48.7) & $8(44.4)$ & $11(42.3)$ & $18(56.3)$ \\
\hline & NSTEMI & $39(51.3)$ & $10(55.6)$ & $15(57.7)$ & $14(43.8)$ \\
\hline \multirow[t]{2}{*}{ Reperfusion } & PCI & $65(85.5)$ & $13(72.2)$ & $25(96.2)$ & 27 (84.4) \\
\hline & PTCA & $4(5.3)$ & $2(11.1)$ & $1(3.8)$ & $1(3.1)$ \\
\hline
\end{tabular}




\begin{tabular}{|c|c|c|c|c|c|}
\hline & None & $7(9.2)$ & $3(16.7)$ & $0(0)$ & $4(12.5)$ \\
\hline Killip & I & $22(28.9)$ & $2(11.1)$ & $6(23.1)$ & $14(43.8)$ \\
\hline & II & $25(32.9)$ & $6(33.3)$ & $8(30.8)$ & $11(34.4)$ \\
\hline & III & $17(22.4)$ & $9(50.0)$ & $6(23.1)$ & $2(6.3)$ \\
\hline LVEF & IV & $12(15.8)$ & $1(5.6)$ & $6(23.1)$ & $5(15.6)$ \\
\hline & $10-50 \%$ & $28(52.8)$ & $11(61.1)$ & $15(57.7)$ & $6(18.8)$ \\
\hline
\end{tabular}

AMI: acute myocardial infarction, BMI: body mass index, LVEF: left ventricular election fraction, NSTEMI: non-ST-elevated myocardial infarction, PCI: percutaneous coronary intervention, PTCA: percutaneous transluminal coronary angioplasty, STEMI: ST-elevated myocardial infraction.

Table 5: Results of group-based trajectory model for PCS.

\begin{tabular}{|c|c|c|c|c|c|c|}
\hline \multicolumn{2}{|c|}{ Group } & $\begin{array}{c}\text { Parameter } \\
\text { estimate }\end{array}$ & SE & t-value & p-value & Group membership \% \\
\hline 1 & Intercept & 30.83 & 2.12 & 14.55 & $<0.001$ & 23.6 \\
\hline & $\beta$ & -0.78 & 0.71 & -1.10 & 0.271 & 34.1 \\
\hline 2 & Intercept & 42.58 & 1.95 & 21.85 & $<0.001$ & 42.3 \\
\hline 3 & $\beta$ & -1.45 & 0.63 & -2.30 & 0.022 & \\
\hline & Intercept & 48.57 & 1.36 & 35.77 & $<0.001$ & \\
\hline
\end{tabular}

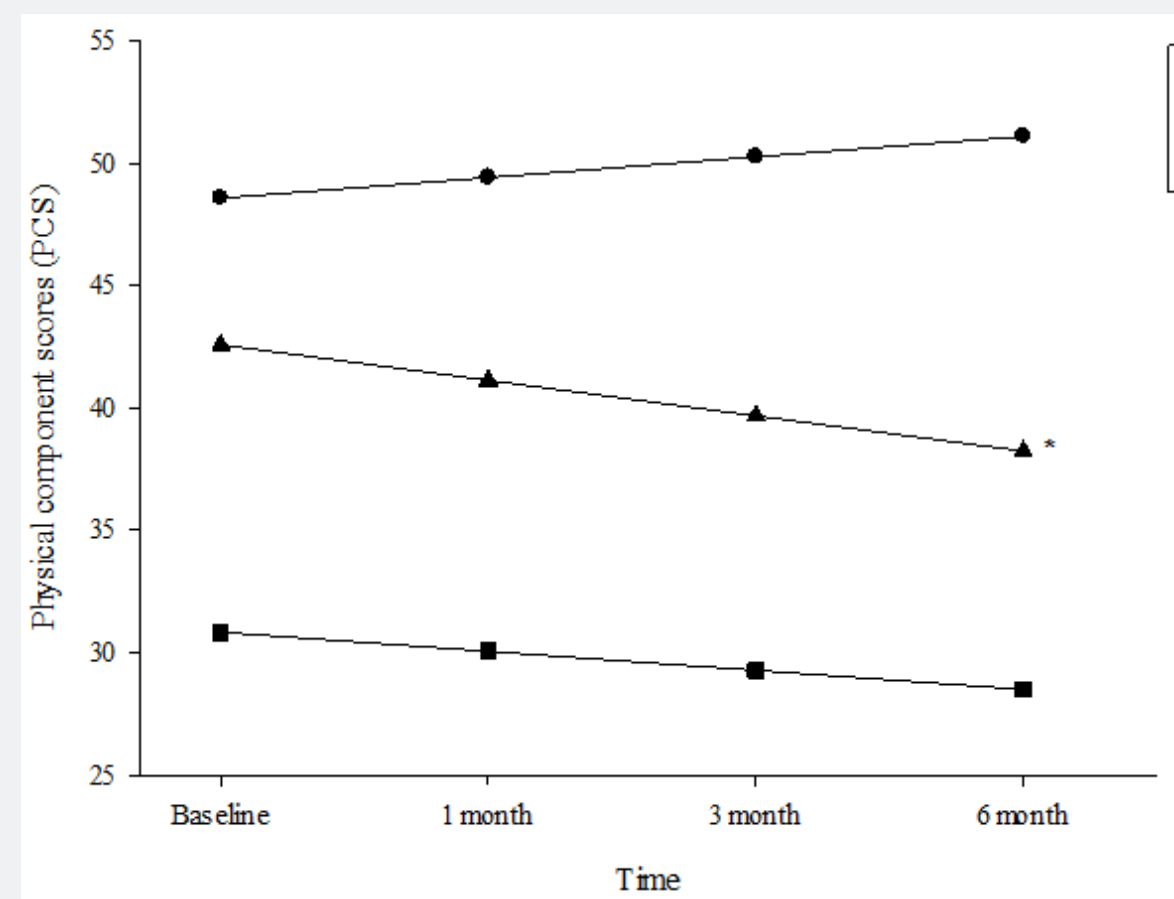

*statistically significant linear trend ( $p$-value $<0.05)$.

Figure 1: Trajectory plots of the three groups for PCS.

\section{Trajectories of MCS}

By using GBTM, four trajectory sub-groups of MCS were identified.As seen in Table 6, the descriptive characteristics of the participants, based on their membership in an MCS trajectory, suggest that male gender, 60 years or older, non-smoker, non-obese, Killip classification greater than III, and NSTEMI participants were overrepresented in the intermediate to low trajectory. In contrast, men under 60 years old, employed, non-smokers. Killip II, and
STEMI participants were overrepresented in the "intermediate to high trajectory" group. The corresponding percentages in each group were: males, $16 \%, 28 \%, 14 \%, 43 \%$; 60 years or older, $6 \%, 29 \%, 10 \%, 41 \%$; and obese, 23\%, 26\%, 19, 32\% (Table 6). For MCS, the second group (36.0\% of participants) showed a statistically significant decreasing trend (slope $(\beta)=-1.38$, p-value $=0.005)$, and the third group (17.16\% of participants) showed a statistically significant increasing trend (slope $(\beta)=2.90$, 
p-value $=0.001)$. The results are presented in Table 7. Figure 2 shows the trajectories of the four sub-groups. For the first group (denoted with a square), the "persistent low trajectory" group, with $5.5 \%$ of participants, the trajectory showed an insignificant trend of MCS level that increased over the observation period (6 months). Although the score declined, it remained higher than the initial score at the end of the observation. The second group (denoted with a cross), the "intermediate to low" trajectory group, comprised $36 \%$ of the participants. The shape of the trajectory shows a statistically significant decreasing trend (slope $(\beta)=-1.38$, p-value $=0.005)$ over the observation period ( 6 months). The third group (denoted with an inverted triangle), the "intermediate to high" trajectory group, (with $17.2 \%$ of the participants) had a statistically positive slope coefficient $($ slope $(\beta)=2.90, p$-value $=0.001$ ). The trajectory characterized a statistically significant increase over the observation period ( 6 months). The fourth group (denoted with a circle), the "persistent high" trajectory, included $41.3 \%$ of the participants. Although starts with a high MCS score, it did not show a statistically significant slope coefficient. The fluctuation of the scores remained within the norm score of general populations. At the end of the observation period, Group 3 (intermediate to high trajectory) ascended to a point similar to that of Group 4. This indicates that these two groups reached the high MCS score at 6 months, regardless of the baseline scores.
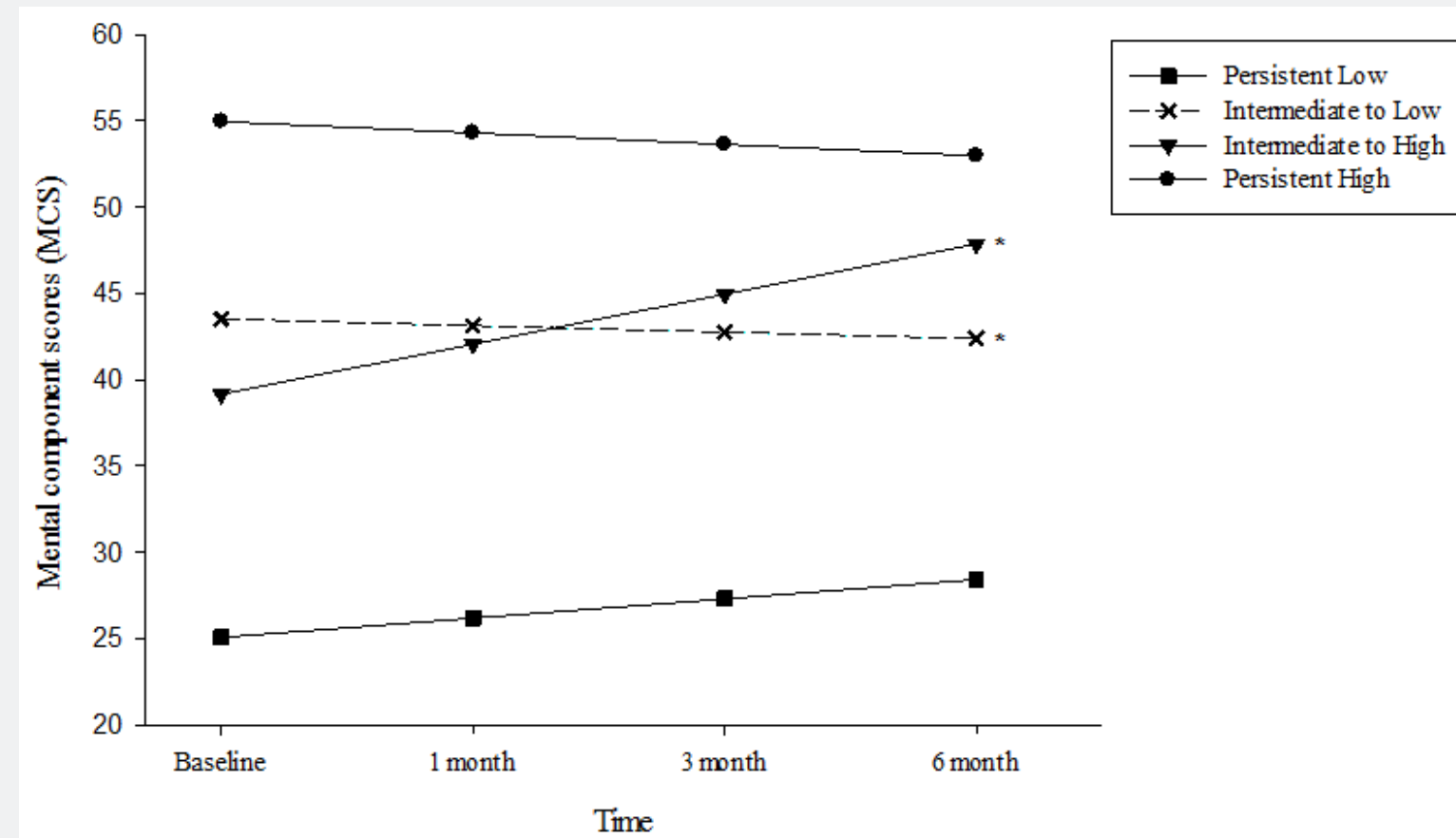

${ }^{*}$ statistically significant linear trend ( $p$-value $\left.<0.05\right)$.

Figure 2: Trajectory plots of the three groups for MCS.

Table 6: Descriptive characteristics of the participants by trajectories of MCS.

\begin{tabular}{|c|c|c|c|c|c|c|}
\hline & & \multicolumn{5}{|c|}{ Trajectory } \\
\hline & & $\begin{array}{c}\text { All } \mathbf{n}=76 \\
n(\%)\end{array}$ & $\begin{array}{c}\text { Persistent Low } \\
\mathbf{n}=\mathbf{1 2} \\
\mathrm{n}(\%)\end{array}$ & $\begin{array}{l}\text { Intermediate to } \\
\text { Low } \mathbf{n}=\mathbf{2 1} \\
\mathrm{n}(\%)\end{array}$ & $\begin{array}{c}\text { Intermediate to } \\
\text { High } \mathbf{n}=11 \\
n(\%)\end{array}$ & $\begin{array}{l}\text { Persistent High } \\
\qquad \begin{array}{c}\mathbf{n}=\mathbf{3 2} \\
\mathrm{n}(\%)\end{array}\end{array}$ \\
\hline \multirow[t]{2}{*}{ Gender } & Male & $58(76.3)$ & $9(75)$ & $16(76.2)$ & 8 (72.7) & $25(78.1)$ \\
\hline & Female & 18 (23.7) & $3(25)$ & $5(23.8)$ & $3(27.3)$ & 7 (21.9) \\
\hline \multirow[t]{2}{*}{ Age } & $18-59$ & $27(35.5)$ & $4(33.3)$ & 7 (33.3) & $6(54.5)$ & $12(37.5)$ \\
\hline & $60-95$ & $49(64.5)$ & 8 (66.7) & $14(66.7)$ & $5(45.5)$ & $20(62.5)$ \\
\hline \multirow[t]{2}{*}{ Employment } & Yes & 41 (53.9) & 5 (41.7) & $12(57.1)$ & 7 (63.6) & 17 (53.1) \\
\hline & No & $35(46.1)$ & 7 (58.3) & $9(42.9)$ & $4(36.4)$ & $15(46.9)$ \\
\hline \multirow[t]{2}{*}{ Living Alone } & Yes & $10(13.2)$ & $1(8.3)$ & $1(4.8)$ & $0(0)$ & $8(25)$ \\
\hline & No & $66(86.8)$ & 11 (91.7) & $20(95.2)$ & $11(100)$ & $24(75)$ \\
\hline Smoking & Yes & $30(39.5)$ & 7 (58.3) & $8(38.1)$ & $5(45.5)$ & $10(31.3)$ \\
\hline
\end{tabular}


JOJ Nursing \& Health Care

\begin{tabular}{|c|c|c|c|c|c|c|}
\hline & No & $46(60.5)$ & $5(41.7)$ & 13 (61.9) & $6(54.5)$ & $22(68.8)$ \\
\hline \multirow[t]{2}{*}{ Alcohol } & Yes & $28(36.8)$ & $6(50)$ & 7 (33.3) & $3(27.3)$ & $12(37.5)$ \\
\hline & No & $48(63.2)$ & $6(50)$ & $14(66.7)$ & $8(72.7)$ & $20(62.5)$ \\
\hline \multirow[t]{2}{*}{ BMI } & Non-obese & $45(59.2)$ & $5(41.7)$ & $13(61.9)$ & $5(45.5)$ & 22 (68.8) \\
\hline & Obese & $31(40.8)$ & 7 (58.3) & 8 (38.1) & $6(54.5)$ & 10 (31.3) \\
\hline \multirow[t]{2}{*}{ AMI type } & STEMI & 37 (48.7) & $4(33.3)$ & 8 (38.1) & 7 (63.6) & $18(56.3)$ \\
\hline & NSTEMI & 39 (51.3) & 8 (66.7) & $13(61.9)$ & $4(36.4)$ & $14(43.7)$ \\
\hline \multirow[t]{3}{*}{ Reperfusion } & PCI & $65(85.5)$ & $10(83.3)$ & $17(81)$ & $10(90.9)$ & $26(81.3)$ \\
\hline & PTCA & $4(5.3)$ & $0(0)$ & $2(9.5)$ & $1(9.1)$ & $1(3.1)$ \\
\hline & None & $7(9.2)$ & $1(8.3)$ & $2(9.5)$ & $0(0)$ & $4(12.5)$ \\
\hline \multirow[t]{4}{*}{ Killip } & I & 22 (28.9) & $2(16.7)$ & $2(9.5)$ & $1(9.1)$ & 17 (53.1) \\
\hline & II & 25 (32.9) & 7 (58.3) & 5 (23.8) & $5(45.5)$ & $8(25)$ \\
\hline & III & $17(22.4)$ & $3(25)$ & 7 (33.3) & 3 (27.3) & $4(12.5)$ \\
\hline & IV & $12(15.8)$ & $0(0)$ & 7 (33.3) & $2(18.2)$ & $3(9.4)$ \\
\hline \multirow[t]{2}{*}{ LVEF } & $10-50 \%$ & $28(52.8)$ & $5(41.7)$ & $14(66.7)$ & $4(36.4)$ & $6(18.8)$ \\
\hline & $51-80 \%$ & $25(47.2)$ & 7 (58.3) & 4 (19) & $5(45.5)$ & $9(28.1)$ \\
\hline
\end{tabular}

Table 7: Results of Group-Based Trajectory model for MCS.

\begin{tabular}{|c|c|c|c|c|c|c|}
\hline \multicolumn{2}{|c|}{ Group } & $\begin{array}{c}\text { Parameter } \\
\text { estimate }\end{array}$ & SE & t-value & p-value & $\begin{array}{c}\text { Group } \\
\text { membership } \%\end{array}$ \\
\hline 1 & Intercept & 25.05 & 3.44 & 7.28 & $<0.001$ & 5.5 \\
\hline & $\beta$ & 1.12 & 1.15 & 0.98 & 0.328 & \\
\hline 2 & Intercept & 43.53 & 1.28 & 34.03 & $<0.001$ & 36 \\
\hline 3 & $\beta$ & -1.38 & 0.49 & -2.83 & 0.005 & 17.2 \\
\hline & Intercept & 39.17 & 2.71 & 14.45 & $<0.001$ & 0.001 \\
\hline & $\beta$ & 2.9 & 0.87 & 3.33 & $<0.001$ & 41.3 \\
\hline
\end{tabular}

\section{Discussion}

In this study of AMI patients, using four repeated measurements of HRQOL over a 6-month period, three distinct trajectories of PCS were identified: "persistent low" (23.6\%), "persistent intermediate" (34.1\%), and "persistent high" (42.3\%) trajectories. Four trajectory groups of MCS also were identified: "persistent low" (5.5\%), "intermediate to low" (36\%), "intermediate to high" (17.2\%), and "persistent high" (41.3\%). This finding confirms our assumption that there are different trajectories of HRQOL in AMI patients. This also explains the insignificant changes in PCS and MCS mean scores over 6 months. Le Grande's study showed that trajectories also were improved after surgery in the CABG population [18]. Other studies have suggested that HRQOL improves at one month after PCI [10]. In contrast, in our study, the PCS trajectories showed a different shape for each group. Group 1's (persistent low) trajectory declined at one month after heart attack, while that of Groups 2 and 3 increased at one month after myocardial infarction. The descriptive data reveal a larger percentage of men, 60 years or older, employed, non-obese, nonsmoker, and STEMI participants in the "persistent high" trajectory group, which is different from Kim's finding that older age was correlated with low HRQOL among STEMI participants who undergo PCI [8]. The interesting finding is that the scores of the PCS trajectories were parallel over the observation period, which may be due to the characteristics of the disease. AMI is an acute life-threatening disease, and over $90 \%$ of patients received PCI or other life-saving interventions. Reperfusion therapy prevents further cardiac damage and preserves cardiac function after a heart attack. Thus, the PCS of quality of life is not significantly affected. Regarding the MCS trajectories, Le Grande also found improvement in both the improvers and non-improvers groups after surgery [18]. Lower baseline scores were significantly associated with previous cardiac surgery and POMS anxiety tension, depression-dejection, and anger. In our study, the MCS trajectories developed a different shape in different groups. The "persistent low" group ascended slightly over time, and the persistent high" group declined slightly. The most interesting findings were for Groups 2 and 3, which started at similar levels at baseline (intercept $=43.53, \mathrm{p}<.001$ vs. intercept $=39.17, \mathrm{p}<$ $.001)$, then dramatically changed in opposite direction over time. Group 2 was characterized by a significant negative slope, while Group 3 developed a positive slope over time.

We identified four trajectories of MCS, a finding similar to that of Virtanen et al. [19], who used a midlife-to-old-age 
population to investigate the correlation of CHD and CHD risk factors on psychological distress trajectory [19]. The results also suggested four trajectories of psychological distress. The largest group was the "low psychological distress" trajectory, and the smallest was the "high psychological distress" trajectory. The findings were similar to those of our study, for which the largest proportion of participants were in the "persistent high" trajectory, and the smallest were in the "persistent low" trajectory of MCS. Non-smoker and obese participants were in higher proportions in both the "low psychological distress" and "persistent high" MCS trajectories. In contrast to previous studies that reported worsening psychological distress and depression trajectories, we identified an "intermediate to high" group (17.2\%) in which MCS improved over time. A higher proportion of participants in this group were men, 60 years and older, employed, non-smoker, Killip I and II, and STEMI. In contrast, in the "intermediate to low" group, there were higher proportions of males, age 60 or older, non-obese, non-smoker, Killip classification greater than III, and STEMI participants (36\%).

\section{Limitations}

Considering the limitations of the study, a replication with a larger number of baseline participants and a longer observation period of AMI patients is needed. The loss to follow-up rate also may have affected the trajectories. Further research also should examine factors such as socio demographic and medically related as well as psychological symptoms, such as depression and anxiety. The results of our study can help clinical professionals to identify high-risk subjects as a means to provide more comprehensive care to AMI patients.

\section{Conclusion}

We used a novel approach to AMI and its HRQOL trajectory, using GBTM. In previous studies on HRQOL in AMI, traditional repeated measures were used to identify the mean trend of quality of life and predictors, and our findings were different from those of the previous studies. We identified individuals' trajectories and clustered significant trajectory groups in both PCS and MCS. We provided a new approach to studying the long-term trajectory of AMI patients. Notably, obesity is an important modifiable factor (to non-obesity) for better HRQOL. Our finding can be used to increase clinicians' awareness of the need to assess the BMI level of older patients and to follow up to prevent further health problems. Our results add evidence to the belief that HRQOL has several trajectories over time after an AMI.

\section{References}

1. Gerber Y, Benyamini Y, Goldbourt U, Drory Y (2009) Prognostic importance and long-term determinants of self-rated health after initial acute myocardial infarction. Med Care 47(3): 342-349.

2. Pavy B, Iliou MC, Höfer S, Vergès Patois B, Corone S, et al. (2015) Validation of the French version of the MacNew heart disease healthrelated quality of life questionnaire. Archives of Cardiovascular Diseases 108(2): 107-117.
3. Pocock S, Bueno H, Licour M, Medina J, Zhang L, et al. (2015). Predictors of one-year mortality at hospital discharge after acute coronary syndromes: A new risk score from the EPICOR (long-tErm follow uP of antithrombotic management patterns In acute CORonary syndrome patients) study. Eur Heart J Acute Cardiovasc Care 4(6): 509-517.

4. Duenas M, Ramirez C, Arana R, Failde I (2011) Gender differences and determinants of health related quality of life in coronary patients: a follow-up study. BMC Cardiovasc Disord 11: 24.

5. Shibayama K (2012) Factors Related to the Improvement of Quality of Life at 6 Months after Discharge for Myocardial Infarction Patients Treated with Percutaneous Coronary Intervention. Journal of Rural Medicine 7(1): 33-37.

6. Worcester MU, Murphy BM, Elliott PC, Le Grande MR, Higgins RO, et al. (2007) Trajectories of recovery of quality of life in women after an acute cardiac event. Br J Health Psychol 12(Pt 1): 1-15.

7. Xue C, Bian L, Xie YS, Yin ZF, Xu ZJ, et al. (2017) Impact of smoking on health-related quality of Life after percutaneous coronary intervention treated with drug-eluting stents: a longitudinal observational study. Health Qual Life Outcomes 15(1): 1.

8. Smolderen KG, Strait KM, Dreyer RP, D`Onofrio G, Zhou S, et al. (2015) Depressive Symptoms in Younger Women and Men With Acute Myocardial Infarction: Insights From the VIRGO Study. Journal of the American Heart Association 4(4).

9. Dreyer RP, Wang Y, Strait KM, Lorenze NP, D’Onofrio G, et al. (2015) Gender differences in the trajectory of recovery in health status among young patients with acute myocardial infarction: results from the variation in recovery: role of gender on outcomes of young AMI patients (VIRGO) study. Circulation 131(22): 1971-1980.

10. Kim MJ, Jeon DS, Gwon HC, Kim SJ, Chang K, et al. (2013) Health-related quality-of-life after percutaneous coronary intervention in patients with UA/NSTEMI and STEMI: the Korean multicenter registry. J Korean Med Sci 28(6): 848-854.

11. Lu Y, Zhou S, Dreyer RP, Spatz ES, Geda M, et al. (2017) Sex Differences in Inflammatory Markers and Health Status Among Young Adults With Acute Myocardial Infarction: Results From the VIRGO (Variation in Recovery: Role of Gender on Outcomes of Young Acute Myocardial Infarction Patients) Study. Circ Cardiovasc Qual Outcomes 10(2): e003470.

12. Buchanan DM, Arnold SV, Gosch KL, Jones PG, Longmore LS, et al. (2015) Association of Smoking Status With Angina and Health-Related Quality of Life After Acute Myocardial Infarction. Circ Cardiovasc Qual Outcomes 8(5): 493-500.

13. Bucholz EM, Strait KM, Dreyer RP, Geda M, Spatz ES, et al. (2014) Effect of Low Perceived Social Support on Health Outcomes in Young Patients With Acute Myocardial Infarction: Results From the Variation in Recovery: Role of Gender on Outcomes of Young AMI Patients (VIRGO) Study. Journal of the American Heart Association 3(5): e001252.

14. Leifheit-Limson EC, Reid KJ, Kasl SV, Lin H, Buchanan DM, et al. (2012) Changes in social support within the early recovery period and outcomes after acute myocardial infarction. J Psychosom Res 73(1): $35-41$.

15. Page KN, Davidson P, Edward KL, Allen J, Cummins RA, et al. (2010) Recovering from an acute cardiac event--the relationship between depression and life satisfaction. J Clin Nurs 19(5-6): 736-743.

16. Palacios J, Khondoker M, Mann A, Tylee A, Hotopf M (2018) Depression and anxiety symptom trajectories in coronary heart disease: Associations with measures of disability and impact on 3-year health care costs. J Psychosom Res 104: 1-8.

17. Sakai M, Nakayama T, Shimbo T, Ueshima K, Kobayashi N, et al. (2011) 


\section{JOJ Nursing \& Health Care}

Post-discharge depressive symptoms can predict quality of life in AM survivors: a prospective cohort study in Japan. Int J Cardiol 146(3): 379-384.

18. Kroemeke A (2016) Depressive symptom trajectories over a 6-year period following myocardial infarction: predictive function of cognitive appraisal and coping. J Behav Med 39(2): 181-191.

19. Virtanen M, Elovainio M, Josefsson K, Batty GD, Singh-Manoux A, et al. (2016) Coronary heart disease and risk factors as predictors of trajectories of psychological distress from midlife to old age. Heart 103(9): 659-665.
20. Le Grande MR, Elliott PC, Murphy BM, Worcester MU, Higgins RO, et al. (2006) Health related quality of life trajectories and predictors following coronary artery bypass surgery. Health Qual Life Outcomes 4: 49 .

21. Nagin DS, Odgers CL (2010) Group-based trajectory modeling in clinical research. Annu Rev Clin Psychol 6: 109-138.

22. Ware JE, Kosinski M, SD K (1995) SF-12: how to score the SF-12 Physical and Mental Health Summary Scales ( $2^{\text {nd }}$ edn.), Boston, New England Medical Center, MA, USA.

\section{Your next submission with Juniper Publishers will reach you the below assets}

- Quality Editorial service

- Swift Peer Review

- Reprints availability

- E-prints Service

- Manuscript Podcast for convenient understanding

- Global attainment for your research

- Manuscript accessibility in different formats

( Pdf, E-pub, Full Text, Audio)

- Unceasing customer service

Track the below URL for one-step submission https://juniperpublishers.com/online-submission.php 